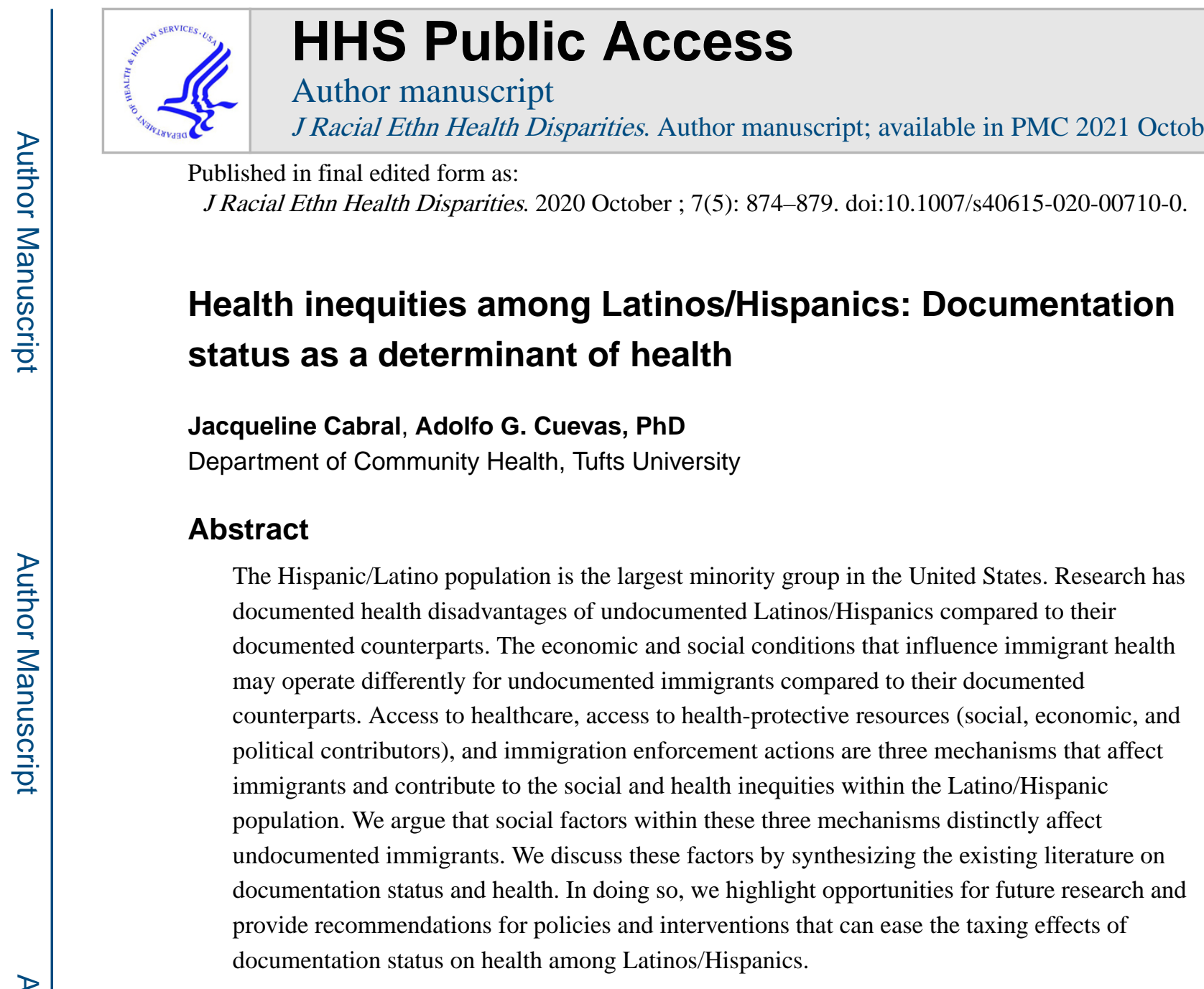

\title{
Introduction
}

Approximately $18 \%$ of the Latino/Hispanic population are undocumented in the United States (US) [1]. Research has documented health disadvantages of undocumented Latinos/ Hispanics compared to their documented counterparts. Undocumented immigrants, regardless of duration, have higher blood pressure compared to documented immigrants who have been in the US for a shorter period of time [2]. Undocumented individuals are more likely to report greater depression and social isolation, higher rates of hypertension with longer length of hospital stay, greater anxiety and post-traumatic stress, and higher levels of acculturative stress compared to documented immigrants [2-5]. Moreover, undocumented immigrants present more advanced stage diseases, such as breast cancer and HIV infection, at the beginning of care than their documented counterparts [6-7]. Concerning maternal and child health, undocumented Latina immigrants are more likely to experience low birth weight cases than documented Latina immigrants [8]. One study revealed that

\footnotetext{
Terms of use and reuse: academic research for non-commercial purposes, see here for full terms. http://www.springer.com/gb/openaccess/authors-rights/aam-terms-v1

Correspondence concerning this article should be addressed to Adolfo G. Cuevas at Tufts University, Department of Community Health, 574 Boston Ave, Suite 208, Medford, MA 02155. Adolfo.cuevas@tufts.edu; Telephone: (617) 627-1026.

Publisher's Disclaimer: This Author Accepted Manuscript is a PDF file of a an unedited peer-reviewed manuscript that has been accepted for publication but has not been copyedited or corrected. The official version of record that is published in the journal is kept up to date and so may therefore differ from this version.
} 
undocumented immigrants have lower odds of self-rated excellent/very good health status compared to documented immigrants [9]. While undocumented immigrants also have lower odds of having physician-diagnosed health outcomes (e.g., asthma, hypertension) [9], this may be a result of undocumented immigrants having limited access to healthcare [9]. Undocumented individuals face extremely limited opportunities for social mobility and are often exposed to social environments with poor access to care, education, and healthpromoting resources. The cumulative effects of these adversities place this group of Latinos/ Hispanics at an increased risk for disease.

Castaneda's structural framework on immigration and health suggests that "large-scale" social forces shape health outcomes of immigrants [10]. While the framework was initially developed to understand the social determinants of immigrant health, the framework can also be applied to understand the social and structural factors that catalyze health differences between documented and undocumented Latino/Hispanic immigrants. According to the framework, the economic and social conditions that influence immigrant health operate through three mechanisms: access to healthcare, access to health-protective resources (social, economic, and political contributors), and immigration enforcement actions [10]. These three mechanisms disproportionately affect undocumented immigrants and contribute to the social and health inequities that exist within the Latino/Hispanic population. While we argue that Castaneda's framework can help explain existing disparities, we illuminate the factors within the three mechanisms that distinctly affect undocumented immigrants. Highlighting these factors can inform interventions and prevention measures that seek to reduce health disparities and inequity within the Latino/Hispanic population.

\section{Access to healthcare}

Approximately $68 \%$ of documented Mexican immigrants have a usual place to go when sick compared to $47 \%$ of undocumented Mexican immigrants [11]. These differences may vary for other Latinos/Hispanic subgroups (e.g., Guatemalans, Dominicans)[12-13]. Since undocumented immigrants are ineligible for Medicaid in certain states, many rely on Emergency Medicaid and the Emergency Medical Treatment and Labor Act [14]. Emergency Medicaid covers emergency care, such as labor and delivery, and it is provided to those who fulfill Medicaid requirements but are ineligible due to status [14]. Undocumented immigrants also receive emergency services through EMTALA [14]. Given that these services strictly administer emergency care, undocumented immigrants substantially resort to safety care services at community health centers and clinics for basic care [15]. Approximately $30 \%$ and $14 \%$ of the services used by undocumented women and men, respectively, are from a combination of Emergency Medicaid and community health centers [16]. The minimal range of health services to undocumented immigrants renders many of them disproportionately dependent on the emergency room for care [17]. This may increase the risk for undocumented immigrants to be diagnosed at an advanced stage of disease when they do present for care.

The legal requirement of proving residency when visiting a doctor establishes a systemic barrier between immigrants and good health [18]. It directly impedes individuals from preventing, treating, and managing the disease on time [18]. Proof of residency to receive 
care also instills a sense of alienation and displacement based on perceived inequalities, lack of quality care, and discrimination within the healthcare system [19-20]. Proof of residency can lead to mistrust toward the healthcare system and their providers and reduce the utilization of healthcare [19]. The fear of deportation can further exacerbate healthcare underutilization [21]. Among the undocumented immigrant community $(\mathrm{N}=143)$, approximately $39 \%$ reported not frequenting social and governmental agencies due to the fear of deportation [21]. Moreover, those who expressed concern with seeking services for fear of deportation, reported higher levels of negative emotional states (e.g., anger) and poorer self-rated health [21].

The effects of documentation status on health do not only burden the undocumented immigrants, but may also spill over into the health of future generations. Approximately 95\% of Mexican American children with documented parents reported their ability to visit a physician compared to $87 \%$ of children with undocumented parents [22]. Since undocumented parents have limited options for public programs, their minimal experience with the healthcare system prevents their children from receiving treatment on time [22]. Latino parents in general report language and cultural barriers, poverty, lack of health insurance, transportation challenges, and long waiting times as healthcare barriers for their children [23]. Combined with the fear of deportation, the lack of educational and financial resources, and the perceived structural barriers, children of undocumented parents are at an increased risk of experiencing unmet medical needs or delayed care [22].

Even when undocumented immigrants receive healthcare, it is not guaranteed that they will receive good quality of care. Although there is no research examining the effects of documentation status on healthcare experiences, there is compelling evidence that racial/ ethnic minorities and uninsured patients receive poorer quality of care compared to white and insured patients [24]. Researchers suggest that racial biases among physicians may in part be explaining treatment differences, and these biases are operating at the unconscious level [25]. For instance, clinicians hold negative stereotypes of racial/ethnic groups and these biases may manifest in non-verbal behaviors and influence decision-making [26]. Implicit biases among physicians is associated with poor health-related outcomes in patients, such as lower adherence to treatment regimen, lower patient satisfaction, and lower overall quality of care [26]. These associations are stronger for Hispanics/Latinos compared to whites [26].

Physicians may have implicit biases toward undocumented immigrants [27]. Reny and Manzano have shown that the media depicts undocumented immigrants as violent or unlawful criminals [28]. Exposure to these negative depictions, both politically and socially, can lead to negative attitudes toward undocumented immigrants, especially among physicians with little exposure to this population. A recent study of a national sample of 1,515 non-Hispanic white adults revealed that participants were more likely to endorse negative stereotypes of undocumented immigrants (e.g., being criminals and violent) compared to documented individuals [29]. These negative attitudes, if also endorsed by physicians, can negatively affect the quality of care undocumented immigrants receive in healthcare. Research is needed to understand the perspective and experiences of providers and undocumented immigrants in healthcare. Improving patient-provider relationship is 
critical for promoting positive health outcomes for undocumented and documented Hispanics/Latinos.

\section{Access to health-protective resources}

Policy, in the form of anti-immigrant laws or sentiments, serves as a structural barrier that affects the immigrant community directly and fosters negative spillover effects onto the Latino/Hispanic communities. Current federal policies targeting undocumented immigrants limit health services, access to state benefits, and restrict labor participation [30]. These harsher policies bolster the effects of existing structural forces that already disadvantage immigrant communities and the Latino population. For example, signage of $287(\mathrm{~g})$ agreements in North Carolina, which had state police reinforce federal immigration policies, correlated with Latina mothers delaying prenatal care and receiving lower quality of care [31]. Proposition 187 in California established a citizenship screening program to prohibit undocumented immigrants from using non-emergency health care and other services [30]. Rates of diagnoses of autism and tuberculosis decreased among Latinos following the implementation of the program, but rose again after the law was repealed [30].

City-level responses through the implementation of sanctuary city policies can act as a protective factor and promote better health outcomes in undocumented individuals. Policies introducing sanctuary spaces address the major contributors to poor health among Latino/ Hispanic individuals as they foster trust in healthcare services, lessen the fear of deportation, and decrease barriers that stem from individual/s legal status [32]. As a result of fostering trust between the immigrant community and the healthcare sector and creating an environment that lessens barriers to care, sanctuary cities showcase better health outcomes among the residing populations. For instance, Iten and colleagues found that undocumented immigrants reported similar clinical outcomes, such as systolic blood pressure and weight, perceptions of the doctor-patient relationship, and ability to maintain diabetes management behaviors, as documented immigrants and US-born Mexican Americans in sanctuary cities [32]. The lack of disparity between the health outcomes of undocumented and documented immigrants can be largely attributed to the protection allotted by a sanctuary city policy. In the face of increasingly anti-immigrant laws in the current political environment, it is imperative that initiatives and policymakers focus on implementing sanctuary spaces to protect the health outcomes of the Latino/Hispanic community as a whole.

\section{Immigration Enforcement Actions}

Anti-immigrant laws, which foster the fear of deportation, have been shown to negatively affect the health of Latinos/Hispanics. For instance, among mixed-status families, those with fear of the deportation of oneself or family member had elevated levels of proinflammatory cytokines, which are markers of chronic stress [33]. Another study found that among Mexican women without baseline hypertension, those who reported a lot or moderate deportation worry were at an increased risk of incident hypertension at the 4-year follow up compared to those reporting not too much worry [34]. The threat of enforcement action can lead to labor exploitation, discrimination, and financial stress, that in turn, can lead to adverse mental and physical health outcomes [35]. For instance, Arizona's SB 1070 Immigration Law, which allowed police to detain individuals who were not able to prove 
their citizenship on request [36], had a profound impact on healthcare utilization among both US-born and foreign-born Mexicans. Foreign-born adolescents reported declines in the use of public assistance, taking their babies to the doctor, and the use of preventive health care after the law was enacted [36]. US-born mothers were also less likely to use public assistance after the SB 1070's enactment [36]. Anderson and colleagues further revealed the harmful effects of Arizona's SB 1070 on the Latino community as they demonstrated that Latino individuals, regardless of documentation status, were more likely to report poorer self-rated health after the passage of SB1070 [37]. Exposure to this policy has also been shown to be associated with lower child birth weight outcomes among Latina immigrant women, compared to US-born Latinas, black, and white women [38].

One of the main repercussions of the current political climate on immigration has been the forced separation of families at the US-Mexico border. Latina immigrant mothers who are separated from their children experience greater rates of major depression compared to those who live with their children [39]. These practices can have detrimental health consequences on immigrant children as well. Studies on Adverse Childhood Experiences consider the prolonged absence of a parent as an adverse childhood event that can lead to poor health in adulthood [40]. One study finds that children who experienced a prolonged absence of a parent have greater perceived stress and more likely to engage in smoking in adulthood [41]. A recent study revealed that unaccompanied children who experienced forced detention had a high incidence of posttraumatic stress, anxiety disorders, depression, aggression, and suicidal ideation [42]. The hostility perpetuated by immigration policies and enforced by agencies causes Hispanic/Latino immigrants to perceive a lack of support from members of their community and have a heightened sense of fear of being harassed by powerful entities [43]. This fear causes distress in children fearing the deportation of their parents [43]. Vargas and colleagues reveal that US Latino families were three times more likely to report optimal child health compared to mixed-status families [43]. Furthermore, the more unfavorable a mixed-status family viewed existing immigration policies, the more likely it was that the child's health would be rated unfavorably [43]. Another study showed that fear of deportation negatively affected Medicaid uptake in mixed-status families [44]. Research on the effects of immigration enforcement actions on child health is very limited. Concerted efforts are needed to examine the interrelationship between documentation status, immigration policy, and childhood health. These findings will help illuminate the long-term health consequences of existing immigration policies.

\section{Conclusion}

Documentation status propels an underlying mechanism by which factors, such as the utilization of resources, stress, and trauma, are propagated and contribute to Latino/Hispanic health. With tougher immigration-related policies and increased anti-immigrant sentiments, documentation status is a potent health risk factor among Latinos/Hispanics. The inequity affecting undocumented immigrants must raise public health concerns and garner heightened focus. Multilevel interventions and programs are needed to ease the effects of documentation status as a social determinant of Latino Health. Castaneda's framework serves to inform interventions and programs at the three structural mechanisms to address the social, economic, institutional, and political structures shaping the health of Latino immigrant 
communities [10]. Undocumented immigrants experience distinct social and economic barriers that places them at an increased risk of illness and disease. Taking into consideration these unique barriers (e.g., fear of deportation, family separation), exceptional prevention and intervention measures are needed:

Policy level advocacy efforts must advocate for fair immigration reform, including a path to citizenship and worker's permit [10]. This will require significant political will and leadership. To enact political and institutional change, research efforts must synthesize the effects of immigration policies on the health of both Latino immigrants and their children. Meanwhile, public health efforts must address the social structures shaping Latino health by advocating for increased resource distribution to health care centers [10], clinics, and hospitals that work community health worker programs. Community health workers can help to reduce cultural and linguistic barriers and expand access to healthcare and insurance coverage [17]. Through these programs, health care settings can adopt more inclusive health care practices. Policy level efforts must focus on improving safety net services in regions where large immigrant populations reside, aside from urban cities [45]. Cities must also advocate for such expansion to categorize immigrant health as a local issue rather than a national issue [45]. Increasing access to care through policy level efforts will require that community-based organizations educate policymakers about the health risks of undocumented immigrants and their children. This would allow policymakers to tailor eligibility criteria to standards fitting the immigrant community. Various states have extended eligibility and demonstrated that it also augments Medicaid enrollment for immigrant children [45]. This effort will require collaborating with community organizations and health centers to promote new standards and to navigate eligibility criteria [45]. Since immigrant communities significantly reply on seeking care at community health centers [10], easier to access community health centers will ensure immigrant communities can continue to seek trusted, quality care.

Community-based interventions must address the social structures reinforcing the lack of access to health-protective resources by teaching Latino/Hispanic individuals about immigrant rights and informing about sanctuary spaces and mental and physical health resources. Having stakeholders facilitate and collaborate with local organizations would help build trust and reduce fear among community members. Interventions and programs seeking to address the impact of documentation status must work closely with immigrant communities to ensure efforts are sustainable and applicable to immigrants [10].

Recognizing documentation status as a social determinant of health is the initial step toward building programs and interventions that are capable of tackling the three structural levels presented. As we continue to learn about the impact of documentation status on health, multi-level efforts like these may help buffer the effects of documentation status on health.

\section{References}

1. Passel JS, Cohn D. Chapter 2: Birthplaces of U.S. Unauthorized Immigrants In: Passel JS, Cohn D. Unauthorized Immigrant Totals Rise in 7 States, Fall in 14: Decline in Those From Mexico Fuels Most State Decreases. 2014. 
2. Young MEDT, Pebley AR. Legal Status, Time in the USA, and the Well-Being of Latinos in Los Angeles. Journal of Urban Health. 2017;94(6):764-775. doi:10.1007/s11524-017-0197-3. [PubMed: 28875414]

3. Sullivan MM, Rehm R. Mental Health of Undocumented Mexican Immigrants. Advances in Nursing Science. 2005;28(3):240-251. doi:10.1097/00012272-200507000-00006. [PubMed: 16106153]

4. Martinez O, Wu E, Sandfort T, et al. Evaluating the Impact of Immigration Policies on Health Status Among Undocumented Immigrants: A Systematic Review. Journal of Immigrant and Minority Health. 2013;17(3):947-970. doi:10.1007/s10903-013-9968-4.

5. Arbona C, Olvera N, Rodriguez N, Hagan J, Linares A, Wiesner M. Acculturative Stress Among Documented and Undocumented Latino Immigrants in the United States. Hispanic Journal of Behavioral Sciences. 2010;32(3):362-384. doi:10.1177/0739986310373210. [PubMed: 25484488]

6. Castro-Echeverry E, Kao LS, Robinson EK, Silberfein EJ, Ko TC, Wray CJ. Relationship between documentation status and survival for medically underserved Hispanic breast cancer patients. Journal of Surgical Research. 2013;180(2):284-289. doi:10.1016/j.jss.2012.04.072. [PubMed: 22632937]

7. Poon KK, Dang BN, Davila JA, Hartman C, Giordano TP. Treatment Outcomes in Undocumented Hispanic Immigrants with HIV Infection. PLoS ONE. 2013;8(3). doi:10.1371/ journal.pone.0060022.

8. Kelaher M, Jessop DJ. Differences in low-birthweight among documented and undocumented foreign-born and US-born Latinas. Social Science \& Medicine. 2002;55(12):2171-2175. doi:10.1016/s0277-9536(01)00360-4. [PubMed: 12409130]

9. Ortega AN, Mckenna RM, Pintor JK, et al. Health Care Access and Physical and Behavioral Health Among Undocumented Latinos in California. Medical Care. 2018; 56(11): 919-926. doi:10.1097/ mlr.0000000000000985 [PubMed: 30216201]

10. Castañeda H, Holmes SM, Madrigal DS, Young M-ED, Beyeler N, Quesada J. Immigration as a Social Determinant of Health. Annual Review of Public Health. 2015;36(1):375-392. doi:10.1146/ annurev-publhealth-032013-182419

11. Bustamante AV, Fang H, Garza J, et al. Variations in Healthcare Access and Utilization Among Mexican Immigrants: The Role of Documentation Status. Journal of Immigrant and Minority Health. 2010; 14(1): 146-155. doi:10.1007/s10903-010-9406-9.

12. Zhen-Duan J, Jacquez F, Vaughn L. Demographic Characteristics Associated With Barriers to Health Care Among Mexican and Guatemalan Immigrants in a Nontraditional Destination Area. Family \& Community Health. 2017;40(2): 101-111. doi:10.1097/fch.0000000000000141 [PubMed: 28207673]

13. Mallet ML, Calvo R, Waters MC. "I Don't Belong Anymore": Undocumented Latino Immigrants Encounter Social Services in the United States. Hispanic Journal of Behavioral Sciences. 2017;39(3):267-282. doi:10.1177/0739986317718530

14. Committee Opinion No. 627 Obstetrics \& Gynecology. 2015;125(3):755-759. doi:10.1097/01.aog.0000461771.63747.37. [PubMed: 25730255]

15. The Henry J. Kaiser Family Foundation. Focus on Health Reform Immigrants' Health Coverage and Health Reform: Key Questions and Answers. https:// kaiserfamilyfoundation.files.wordpress.com/2013/01/7982.pdf 122009 Accessed January 22, 2019

16. Goldman DP, Smith JP, Sood N. Immigrants And The Cost Of Medical Care. Health Affairs. 2006;25(6): 1700-1711. doi:10.1377/hlthaff.25.6.1700. [PubMed: 17102196]

17. Samra S, Taira B, Pinheiro E, Trotzky-Sirr R, Schneberk T. Undocumented Patients in the Emergency Department: Challenges and Opportunities. Western Journal of Emergency Medicine, Volume 20, Issue 5 Western Journal of Emergency Medicine. 2019;20(5):791-798. doi:10.5811/ westjem.2019.7.41489

18. Marshall KJ, Urrutia-Rojas X, Mas FS, Coggin C. Health Status and Access to Health Care of Documented and Undocumented Immigrant Latino Women. Health Care for Women International. 2005;26(10):916-936. doi:10.1080/07399330500301846. [PubMed: 16263663]

19. Calvo R, Jablonska-Bayro J., \& Waters MC. Obamacare in action: How access to the health care system contributes to immigrants' sense of belonging. Journal of Ethnic and Migration Studies. 2017;43(12), 2020-2036. 
20. Santillan M, \& De Maria F. Access to Healthcare, Barriers, Experiences and Disease Perceptions of the Latino Undocumented-Diabetes Mellitus Population in Philadelphia. Graduate Annual. 2014;2(1), 13.

21. Cavazos-Rehg PA, Zayas LH, Spitznagel EL. Legal Status, Emotional Well-Being and Subjective Health Status of Latino Immigrants. Journal of the National Medical Association. 2007; 99(10): 1126-1131. [PubMed: 17987916]

22. Oropesa RS, Landale NS, Hillemeier MM. Legal Status and Health Care: Mexican-Origin Children in California, 2001-2014. Population Research and Policy Review. 2016;35(5):651-684. doi:10.1007/s11113-016-9400-6. [PubMed: 27867239]

23. Flores G, Abreu M, Olivar MA, Kastner B. Access Barriers to Health Care for Latino Children. Archives of Pediatrics \& Adolescent Medicine. 1998; 152( 11). doi:10.1001/archpedi.152.11.1119.

24. Fiscella K, Sanders MR. Racial and Ethnic Disparities in the Quality of Health Care. Annual Review of Public Health. 2016;37(1):375-394. doi:10.1146/annurev-publhealth-032315-021439.

25. Blair IV, Steiner JF, Fairclough DL, et al. Clinicians Implicit Ethnic/Racial Bias and Perceptions of Care Among Black and Latino Patients. The Annals of Family Medicine. 2013;11(1):43-52. doi:10.1370/afm.1442. [PubMed: 23319505]

26. Hall WJ, Chapman MV, Lee KM, et al. Implicit Racial/Ethnic Bias Among Health Care Professionals and Its Influence on Health Care Outcomes: A Systematic Review. American Journal of Public Health. 2015;105(12). doi:10.2105/ajph.2015.302903.

27. Matthew DB. Toward a Structural Theory of Implicit Racial and Ethnic Bias in Health Care. Health Matrix: The Journal of Law-Medicine. 2015; 25(1): 61-86.

28. Reny T, Manzano S. The Negative Effects of Mass Media Stereotypes of Latinos and Immigrants. Media and Minorities. 2016:195-212. doi:10.13109/9783666300882.195.

29. Flores RD, Schachter A. Who are the "Illegals"? The Social Construction of Illegality in the United States. American Sociological Review. 2018;83(5):839-868. doi:10.1177/0003122418794635.

30. Philbin MM, Flake M, Hatzenbuehler ML, Hirsch JS, State-level immigration and immigrantfocused policies as drivers of Latino health disparities in the United States, Social Science \& Medicine (2017), doi: 10.1016/j.socscimed.2017.04.007.

31. Rhodes SD, Mann L, Simán FM, et al. The Impact of Local Immigration Enforcement Policies on the Health of Immigrant Hispanics/Latinos in the United States. American Journal of Public Health. 2015;105(2):329-337. doi:10.2105/ajph.2014.302218 [PubMed: 25521886]

32. Iten AE, Jacobs EA, Lahiff M, Fernández A. Undocumented Immigration Status and Diabetes Care Among Mexican Immigrants In Two Immigration "Sanctuary" Areas. Journal of Immigrant and Minority Health. 2012;16(2):229-238. doi:10.1007/s10903-012-9741-0

33. Martinez AD, Ruelas L, \& Granger DA. Household fear of deportation in relation to chronic stressors and salivary proinflammatory cytokines in Mexican-origin families post-SB 1070. SSMpopulation health. 2018; 5, 188-200. [PubMed: 30073186]

34. Torres JM, Deardorff J, Holland N, Harley KG, Kogut K, Long K, \& Eskenazi B. Deportation Worry, Cardiovascular Disease Risk Factor Trajectories, and Incident Hypertension: A Community-Based Cohort Study. Journal of the American Heart Association. 2019;8(23), e013086. [PubMed: 31771437]

35. Dow HD. An Overview of Stressors Faced by Immigrants and Refugees: A Guide for Mental Health Practitioners. Home Health Care Management \& Practice. 2011;23(3):210-217. doi:10.1177/1084822310390878.

36. Toomey RB, Umana-Taylor AJ, Williams DR, Harvey-Mendoza E, Jahromi LB, Updegraff KA. Impact of Arizona's SB 1070 Immigration Law on Utilization of Health Care and Public Assistance Among Mexican-Origin Adolescent Mothers and Their Mother Figures. American Journal of Public Health. 2014;104(S1). doi:10.2105/ajph.2013.301655.

37. Anderson KF, Finch JK. Racially Charged Legislation and Latino Health Disparities: The Case of Arizonas S.B. 1070. Sociological Spectrum. 2014;34(6):526-548. doi:10.1080/02732173.2014.947452

38. Torche F, Sirois C. Restrictive Immigration Law and Birth Outcomes of Immigrant Women. American Journal of Epidemiology. 2018;188(1):24-33. doi:10.1093/aje/kwy218 
39. Miranda J, Siddique J, Der-Martirosian C, Belin TR. Depression Among Latina Immigrant Mothers Separated From Their Children. Psychiatric Services. 2005;56(6):717-720. doi:10.1176/ appi.ps.56.6.717. [PubMed: 15939949]

40. Mersky J, Topitzes J, Reynolds A. Impacts of adverse childhood experiences on health, mental health, and substance use in early adulthood: A cohort study of an urban, minority sample in the U.S. Child Abuse \& Neglect. 2013;37(11):917-925. doi:10.1016/j.chiabu.2013.07.011. [PubMed: 23978575]

41. Mersky JP, Janczewski CE, Topitzes J. Rethinking the Measurement of Adversity. Child Maltreatment. 2017;22(1):58-68. doi:10.1177/1077559516679513. [PubMed: 27920222]

42. Teicher MH. Childhood trauma and the enduring consequences of forcibly separating children from parents at the United States border. BMC Medicine. 2018;16(1). doi:10.1186/ s12916-018-1147-y.

43. Vargas ED, Ybarra VD. U.S. Citizen Children of Undocumented Parents: The Link Between State Immigration Policy and the Health of Latino Children. Journal of Immigrant and Minority Health. 2016;19(4):913-920. doi:10.1007/s10903-016-0463-6.

44. Vargas ED. Immigration enforcement and mixed-status families: The effects of risk of deportation on Medicaid use. Children and Youth Services Review. 2015;57:83-89. doi:10.1016/ j.childyouth.2015.07.009 [PubMed: 26435562]

45. Derose KP, Escarce JJ, Lurie N. Immigrants And Health Care: Sources Of Vulnerability. Health Affairs. 2007;26(5):1258-1268. doi:10.1377/hlthaff.26.5.1258. [PubMed: 17848435] 


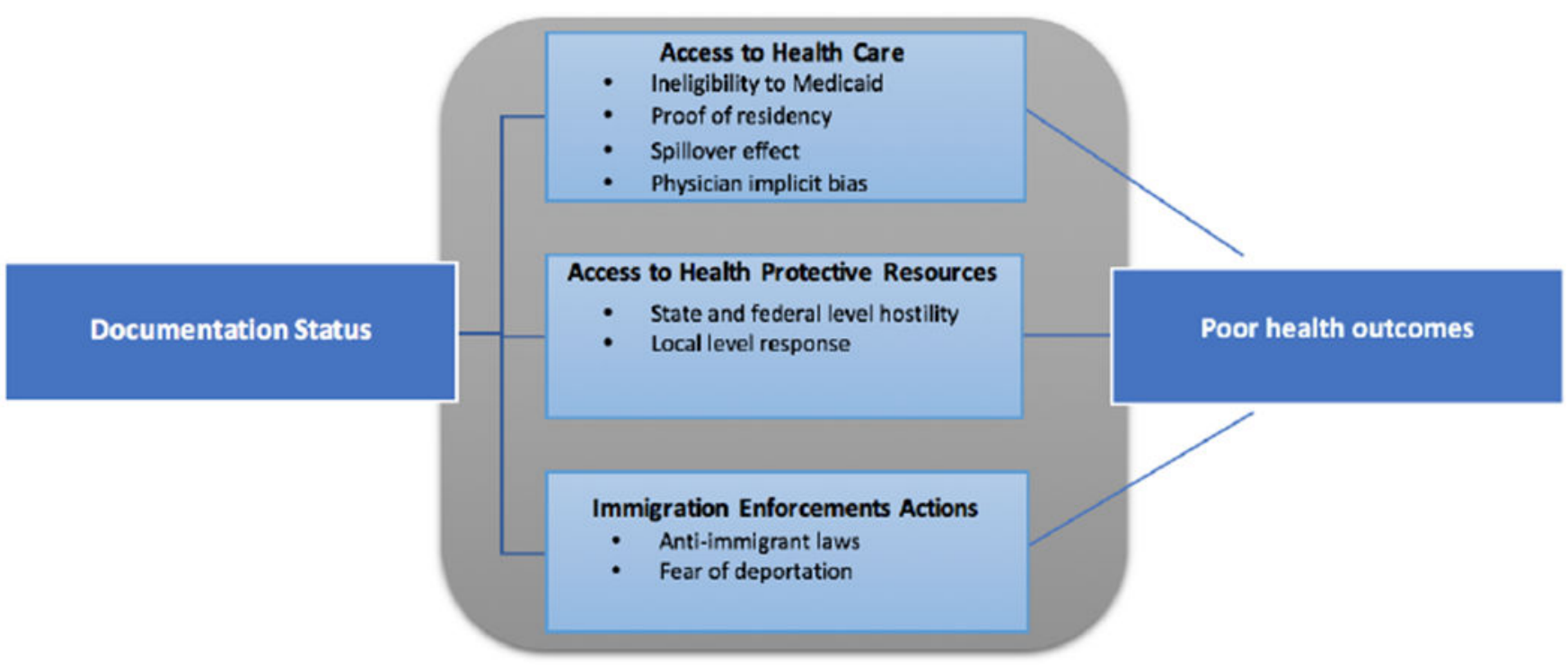

Figure 1.

An adapted version of Castañeda's framework. 